\title{
Penguatan Pendidikan Karakter dalam Proses Pembelajaran Bahasa Inggris
}

\author{
Meita Septiana Wardani ${ }^{1)}$, Nur Rahmah Irianti Nugroho²), \\ Muhammad Taufiq Ulinuha ${ }^{3)}$ \\ 1,2,3)Fakultas Keguruan dan Ilmu Pendidikan \\ Universitas Muhammadiyah Surakarta \\ a320170053@student.ums.ac.id \\ doi: $x x x$ xxx xxx
}

\begin{abstract}
Abstrak: Seiring dengan perkembangan zaman dan kemajuan teknologi, bangsa Indonesia sudah mampu mengukir prestasi di kancah internasional, tidak ketinggalan bidang pendidikan, banyak pelajar Indonesia berhasil menjuarai olimpiade ditingkat dunia. Namun, tidak sedikit pula pelajar yang tidak punya tata krama, suka tawuran, minum minuman keras, kecanduan narkotika, dan hobi kebut-kebutan mengendarai sepeda motor di jalan raya. Kenyataan ini berbanding terbalik dengan tujuan pendidikan nasional dimana pendidikan nasional berfungsi mengembangkan kemampuan dan membentuk watak serta peradaban bangsa yang bermartabat dalam rangka mencerdaskan kehidupan bangsa, bertujuan untuk berkembangnya potensi peserta didik agar menjadi manusia yang beriman dan bertakwa kepada Tuhan Yang Maha Esa, berakhlak mulia, sehat, berilmu, cakap, kreatif, mandiri, dan menjadi warga negara yang demokratis serta bertanggung jawab, melalui Peraturan Presiden (Perpres) No. 87 Tahun 2017 tentang Penguatan Pendidikan Karakter, pemerintah lebih memperkuat pelaksanaan pendidikan karakter pada satuan pendidikan, telah teridentifikasi 18 nilai pembentuk karakter dan 5 karakter utama PPK yang bersumber dari agama, Pancasila, budaya, dan tujuan pendidikan nasional. Sejalan dengan hal tersebut Muhammadiyah melalui amal usaha yang mengelola lembaga pendidikan jauh sebelumnya sudah terlebih dahulu menggalakkan penguatan pendidikan karakter melalui tata krama dan akhlak serta peraturan untuk siswanya.
\end{abstract}

Kata Kunci : Penguatan, Tujuan, Perpres 87, Pembentuk, dan Muhammadiyah.

\section{Pendahuluan}

Pendidikan merupakan usaha sadar dan terencana untuk mewujudkan suasana belajar dan proses pembelajaran agar peserta didik secara aktif mengembangkan potensi dirinya untuk memiliki kekuatan spiritual keagamaan, pengendalian diri, kepribadian, kecerdasan, akhlak mulia, serta keterampilan yang diperlukan dirinya dan masyarakat. Adapun Pendidikan Nasional berfungsi mengembangkan kemampuan dan membentuk watak serta peradaban bangsa yang bermartabat dalam rangka mencerdaskan kehidupan bangsa, bertujuan untuk berkembangnya potensi peserta didik agar menjadi manusia yang beriman dan bertakwa kepada Tuhan Yang Maha Esa, berakhlak mulia, sehat, berilmu, cakap, kreatif, mandiri, dan menjadi warga negara yang demokratis serta bertanggung jawab (UU No. 20 Tahun 2003). Secara 
formal upaya menyiapkan kondisi, sarana/prasarana, kegiatan, pendidikan, dan kurikulum yang mengarah kepada pembentukan watak dan budi pekerti generasi muda memiliki landasan yuridis yang kuat. Namun, sinyal tersebut baru disadari ketika terjadi krisis akhlak yang menerpa semua lapisan masyarakat. Tidak terkecuali juga pada anakanak usia sekolah. Untuk mencegah lebih parahnya krisis akhlak, kini upaya tersebut mulai dirintis melalui pendidikan karakter bangsa.

1400 tahun yang lalu Nabi Muhammad SAW juga menegaskan bahwa misi utamanya adalah mendidik manusia untuk menyempurnakan akhlak dan pengupayaan pembentukan karakter yang baik (good character). Selain itu tokoh pendidikan barat seperti Klipatrick, Lickona, Brooks, dan Goble mengembangkan pemikiran Nabi Muhammad SAW dan Socrates, bahwasanya moral, akhlak, dan karakter adalah tujuan dari Pendidikan. Martin Luther King mengatakan "Intelligence plus character, that is the true aim of education".

Kemudian sebagai penyempurnaan Kurikulum Tingkat Satuan Pendidikan (KTSP) disusunlah Kurikulum 2013 (K13) yang berbasis pendidikan karakter dengan pendekatan scientific. Adapaun K13 mengajak guru untuk mulai mengajarkan pendidikan karakter kepada para siswa sejak dini, di dalam Penguatan Pendidikan Karakter (PPK) terdapat lima nilai karakter utama yang bersumber dari Pancasila, yang menjadi prioritas pengembangan gerakan PPK yaitu religius, nasionalisme, integritas, kemandirian, dan kegotongroyongan.

Nilai karakter religius mencerminkan keberimanan terhadap Tuhan Yang Maha Esa yang diwujudkan dalam perilaku melaksanakan ajaran agama dan kepercayaan yang dianut, menghargai perbedaan agama, menjunjung tinggi sikap toleran terhadap pelaksanaan ibadah agama dan kepercayaan lain, hidup rukun dan damai dengan pemeluk agama lain. Implementasi nilai karakter religius ini ditunjukkan dalam sikap cinta damai, toleransi, menghargai perbedaan agama dan kepercayaan, teguh pendirian, percaya diri, kerja sama antar pemeluk agama dan kepercayaan, anti perundungan dan kekerasan, persahabatan, ketulusan, tidak memaksakan kehendak, mencintai lingkungan, melindungi yang kecil dan tersisih.

Nilai karakter nasionalis merupakan cara berpikir, bersikap, menunjukkan kesetiaan, kepedulian, dan penghargaan yang tinggi dan berbuat yang terhadap bahasa, lingkungan fisik, sosial, budaya, ekonomi, dan politik bangsa, menempatkan kepentingan bangsa dan negara di atas kepentingan diri dan kelompoknya. Sikap nasionalis ditunjukkan melalui sikap apresiasi budaya bangsa sendiri, menjaga kekayaan budaya bangsa, rela berkorban, unggul, dan berprestasi, cinta tanah air, menjaga 
lingkungan, taat hukum, disiplin, menghormati keragaman budaya, suku, dan agama.

Nilai karakter integritas merupakan nilai yang mendasari perilaku yang didasarkan pada upaya menjadikan dirinya sebagai orang yang selalu dapat dipercaya dalam perkataan, tindakan, dan pekerjaan, memiliki komitmen dan kesetiaan pada nilai-nilai kemanusiaan dan moral. Karakter integritas meliputi sikap tanggung jawab sebagai warga negara, aktif terlibat dalam kehidupan sosial, melalui konsistensi tindakan dan perkataan yang berdasarkan kebenaran.

Nilai karakter mandiri merupakan sikap dan perilaku tidak bergantung pada orang lain dan mempergunakan segala tenaga, pikiran, waktu untuk merealisasikan harapan, mimpi dan cita-cita. Siswa yang mandiri memiliki etos kerja yang baik, tangguh, berdaya juang, profesional, kreatif, keberanian, dan menjadi pembelajar sepanjang hayat.

Nilai karakter gotong royong mencerminkan tindakan menghargai semangat kerjasama dan bahu-membahu menyelesaikan persoalan bersama, menjalin komunikasi dan persahabatan, memberi bantuan/pertolongan pada orang-orang yang membutuhkan. Diharapkan siswa dapat menunjukkan sikap menghargai sesama, dapat bekerja sama, inklusif, mampu berkomitmen atas keputusan bersama, musyawarah mufakat, tolong- menolong, memiliki empati dan rasa solidaritas, anti diskriminasi, anti kekerasan, dan sikap kerelawanan.

Namun, sayangnya walaupun sekarang sudah dimulai pendidikan karakter, ternyata para guru masih mengalami kesulitan dalam membentuk karakter siswa terutama pada lima nilai karakter utama PPK, terutama pada nilai integritas. Maka dari itu kami sebagai penulis yang telah melakukan observasi terhadap siswa-siswi di SMP Muhammadiyah 1 Kartasura ingin menuangkan gagasan kami di dalam artikel ilmiah, yang mana kami ingin melihat sejauh mana PPK terutama nilai integritas siswa sudah diterapkan dan diaplikasikan di SMP Muhammadiyah 1 Kartasura.

Tujuan kami sebagai penulis menulis artikel ini adalah agar dapat mengetahui sejauh mana PPK terutama nilai integritas siswa di SMP Muhammadiyah 1 Kartasura terealisasikan, disamping itu kami juga ingin mengurai masalah yang menjadikan PPK terutama nilai integritas mengalami kesulitan dalam praktik di dalam pembelajaran siswa.

\section{Metode}

Metode yang kami gunakan dalam penyusunan artikel ini adalah observartif. Sumber data kami peroleh dari guru-guru dan para siswa SMP Muhammdiyah 1 Kartasura. Teknik yang kami gunakan adalah dengan melakukan observasi secara langsung di dalam kelas, melihat interaksi antara siswa dengan guru dan sebaliknya, serta internalisasi nilai-nilai 
PPK di dalam proses belajar mengajar yang dilakukan oleh guru kepada siswa. Lokasi penelitian kami adalah SMP Muhammadiyah 1 Kartasura yang beralamat di Jl. Ahmad Yani No 160, Kartasura, Kec. Kartasura, Kab. Sukoharjo Prov. Jawa Tengah 57161. Kegiatan observasi dilakukan bersamaan dengan PLP 1 pada tanggal 29 Januari sampai 12 Februari di SMP Muhammadiyah 1 Kartasura. Sedangkan observasi dilakukan pada saat KBM mata pelajaran Bahasa Inggris hari Kamis, 7 Februari 2019.

\section{Hasil dan Pembahasan}

Di awal sudah kami sampaikan dalam pelaksanaan PPK terdapat lima nilai utama yang diharapkan mampu ditanamkan kepada siswa melalui proses kegiatan belajar mengajar di dalam maupun di luar kelas, yang mana penanaman nilai ini bertujuan untuk perbaikan dan penguatan karakter siswa. Berikut kami sampaikan bagan nilai utama pendidikan karakter.

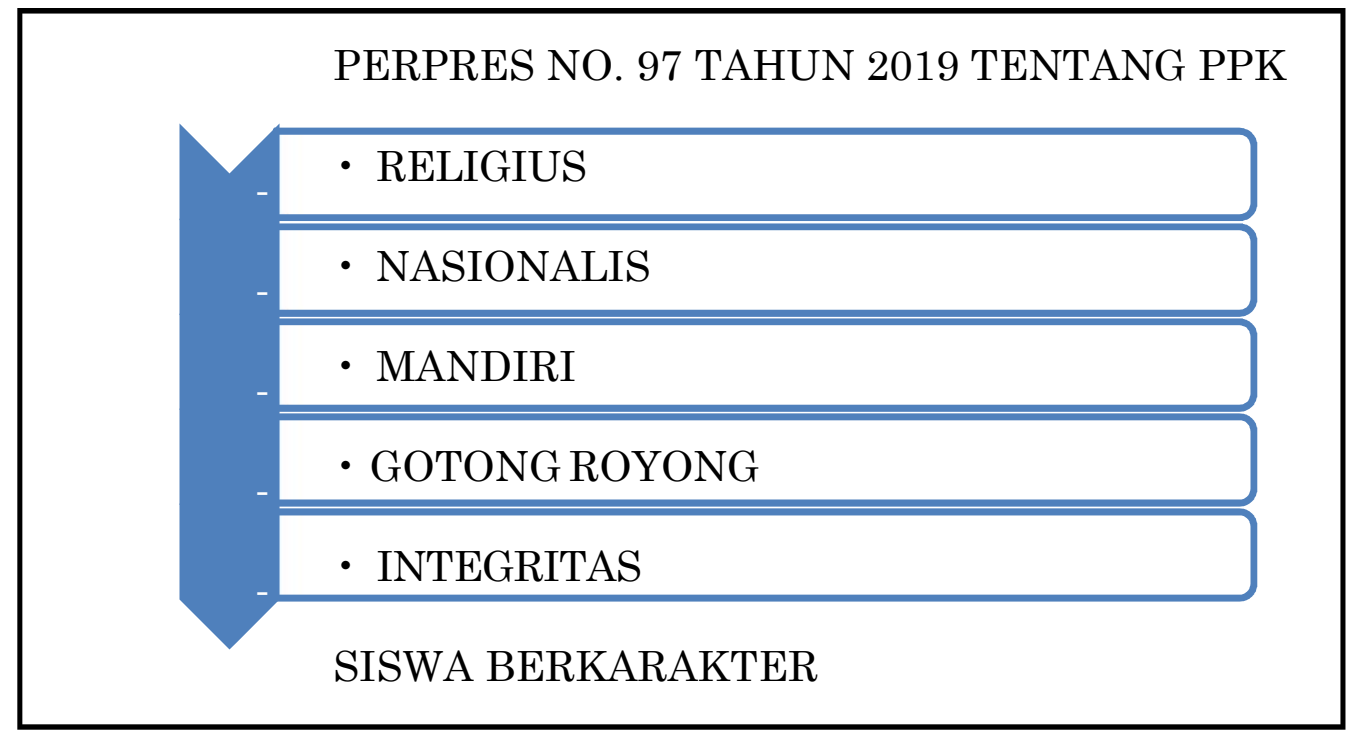

Gambar 1. Bagan Nilai Utama Penguatan Pendidikan Karakter

Bahwasanya sebagai implementasi peraturan pemerintah, SMP Muhammadiyah 1 Kartasura telah menerapkan K13 bagi kelas 7 dan 8 . Sebagai contoh implementasi K13 pada kegiatan-kegiatan siswa kami sajikan dalam tabel di bawah ini. 
Tabel 1. Impementasi Nilai Karakter

\begin{tabular}{|c|l|l|}
\hline No & $\begin{array}{l}\text { Karakter Utama } \\
\text { PPK }\end{array}$ & \multicolumn{1}{|c|}{ Implementasi } \\
\hline 1 & Religius & $\begin{array}{l}\text { Melaksanakan sholat berjama'ah Melaksanakan } \\
\text { Sholat Dhuha } \\
\text { Melakukan muroja'ah Al Qur'an setiap setelah } \\
\text { sholat }\end{array}$ \\
\hline 2 & Nasionalis & $\begin{array}{l}\text { Berbagi makanan ketika istirahat } \\
\text { Melakukan upacara bendera setiap hari senin } \\
\text { Melaksanakan tata tertib dengan baik }\end{array}$ \\
\hline 3 & Mandiri & $\begin{array}{l}\text { Melakukan tugas individu secara pribadi } \\
\text { Berangkat sekolah sendiri (tidak diantar orang } \\
\text { tua) } \\
\text { Memiliki kreativitas dan inovasi }\end{array}$ \\
\hline 4 & Gotong Royong & $\begin{array}{l}\text { Melakukan piket kelas sesuai jadwal yang } \\
\text { ditentukan } \\
\text { Melakukan piket melipat tikar sesuai jadwal }\end{array}$ \\
\hline 5 & Integritas & $\begin{array}{l}\text { Bertanggung jawab dengan tugas yang diberikan } \\
\text { Menghargai teman di dalam maupun di luar kelas } \\
\text { Menjadi teladan bagi teman dan adik kelas }\end{array}$ \\
\hline
\end{tabular}

Dari berbagai contoh kegiatan tersebut kami melihat bahwa sudah terdapat berbagai upaya dalam penanaman kelima nilai utama PPK, namun di dalam praktiknya masih terdapat berbagai kekurangan di beberapa nilai, salah satunya adalah nilai integritas.

Berdasarkan observasi dan pengamatan yang kami lakukan, penanaman nilai integritas siswa di SMP Muhammadiyah 1 Kartasura terdapat beberapa ketidaksesuaian dengan arahan K13, yang mana nilai integritas meliputi : kejujuran, keadilan, keteladanan, kesetiaan, mengahgai orang lain, anti korupsi, komitmen moral, tanggung jawab, dan cinta kebenaran (cerdasberkarakter.kemendikbud.go.id).

Berdasarkan observasi pada mata pelajaran Bahasa Inggris kelas 8 C terdapat beberapa hal yang kami rasa belum mencerminkan nilai integritas, diantaranya:

1. Ketika KBM sudah dimulai dan guru sudah berada di dalam kelas, masih terdapat siswa-siswi yang makan.

2. Beberapa siswa-siswi masih berada diluar kelas ketika guru sudah berada di dalam kelas.

3. Terdapat siswa-siswi yang tidak bersepatu (menggunakan sandal) 
ketika proses KBM berlangsung.

4. Tidak melaksanakan teguran guru ketika diminta menggunakan sepatu dan teguran tersebut harus diulang beberapa kali.

5. Tidak mengerjakan pekerjaan rumah (PR) pertemuan sebelumnya.

6. Berbicara dengan teman sebelahnya saat guru sedang menjelaskan materi.

7. Mengerjakan tugas dengan asal-asalan, dikarenakan tidak paham materi dan tidak mau bertanya kepada guru.

Dalam setiap pelaksanaan sistem, apalagi K13 yang masih dikategorikan baru dilaksanakan secara masif, pasti terdapat problematika seperti yang sudah kami paparkan di atas, utamanya internalisasi nilai integritas pada seluruh siswa. Meskipun demikian guna meminimalisir dan sedikit demi sedikit menanggulangi problematika tersebut alangkah lebih baik apabila guru dan sekolah melakukan beberapa hal, diantaranya:

1. Guru dan sekolah menegakkan disiplin aturan kepada seluruh siswa.

2. Guru dan sekolah memberikan teladan dan contoh kepada siswa.

3. Guru dan sekolah melaksanakan pembelajaran secara aktif, partisipatif dan kolaboratif.

4. Guru dan sekolah menggunakan metode yang sesuaidengan bahasan pembelajaran dan kondisi kelas.

5. Guru dan sekolah melakukan inovasi terhadap metode pembelajaran yang digunakan.

6. Guru dan sekolah mengajak orang tua untuk berperan aktif dalam internalisasi lima nilai utama PPK terutama di rumah.

Dengan pembenahan dan evaluasi terhadap proses pembelajaran, nilai-nilai utama PPK diharapkan mampu diimplementasikan guru di dalam proses pembelajaran secara maksimal. Selain itu secara berangsur SMP Muhammadiyah 1 Kartasura akan mampu melaksanakan K13 secara keseluruhan.

\section{Simpulan}

SMP Muhammadiyah 1 Kartasura sebagai sekolah yang menggunakan K13 dalam sistem pembelajarannya, sudah menerapkan kegiatan yang dapat menanamkan lima nilai utama PPK. Sayangnya, praktik dalam menerapkan lima nilai utama di SMP Muhammadiyah 1 Kartasura masih belum maksimal, terutama nilai integritas. Terdapat beberapa ketidaksesuaian dalam praktiknya dengan arahan K13 sebab adanya halangan yang pada umumnya dalam menerapkan nilai-nilai PPK dikarenakan faktor internal siswa antara lain kurangnya kesadaran dan keseriusan siswa dalam melaksanakan tugas, terutama tugas-tugas 
sekolah seperti mengerjakan soal. Selain itu, siswa juga tidak perpakaian sesuai peraturan sekolah yang berlaku.

\section{Daftar Pustaka}

Republik Indonesia. 2003. Undang-Undang No. 20 Tahun 2003 tentang Sistem Pendidikan Nasional. Lembaran Negara RI Tahun 2003, No. 78. Sekretariat Negara. Jakarta.

Republik Indonesia. 2017. Peraturan Presiden No. 87 Tahun 2017 tentang Penguatan Pendidikan Karakter. Lembaran Negara RI Tahun 2017, No. 195. Sekretariat Kabinet. Jakarta.

Yufer Kusnoto. 2017. Internalisasi Nilai-Nilai Pendidikan Karakter Pada Satuan Pendidikan. Sosial Horizon : Jurnal Pendidikan Sosial. 4(2): 247-256.

Endang Komara. 2018. Penguatan Pendidikan Karakter dan Pembelajaran Abad 21.

South-East Asian Journal for Youth, Sport \& Health Education. 4 (1): 1724. Zulawarman.

Al Rasyidin. Ali Imran Sinaga. 2017. Implementasi Nilai-

Nilai Pendidikan Karakter Pada K13 Dalam PAI Dan Budi

Pekerti Di SMP Al Amjad Medan Sunggal. Edu Religia. 1(4): 558-570.

Yetri. Rijal Firdaos. 2017. Penguatan Pendidikan Karakter Berbasis Masyarakat Pada Sekolah Menengah Pertama Negri (SMPN) Di Kabupaten Tulang Bawang Provinsi Lampung. Al-Tadzkiyyah : Jurnal Pendidikan Islam. 8(2) : 267-277.

Atik Maesaro. Bambang Budi Wiyono. Imron Arifin. 2018. Manajemen Program Penguatan Pendidikan Karakter Di Sekolah Dasar. JAMP : Jurnal Administrasi dan Manajemen Pendidikan. 1(3): 302-311.

Taqiudin Zarkasi. Al Kusaeri. 2018. Penguatan Pendidikan Karakter Di Madrasah (Perpres No 68 Tahun 2017). Jurnal Al Muta'aliyah STAI Darul Kamal NW Kembang Kerang. 1(3): 1-17.

Samrin. 2016. Pendidikan Karakter (Sebuah Pendekatan Nilai). Jurnal Al Ta'dib. 9(1): 120-142.

Iskandar Agung. 2017. Peran Fasilitator Guru Dalam Penguatan Pendidikan Karakter (PPK). Jurnal Prespektif Ilmu Pendidikan. 31(2): 106-118.

Isa Ansori. 2017. Penguatan Pendidikan Karakter Di Madrasah. Halaqa : Islamic Education Journal. 1(2): 11-21.

Kementrian Kesehatan. 2019. Penguatan Pendidikan Karakter Jadi Pintu Masuk Pembenahan Pendidikan Nasional. Diambil dari : www.depkes.go.id. (20 Februari 2019) 